Jacob Steinwede

Entwicklungschancen sozialdemokratischer Parteien 
Studien zur Sozialwissenschaft

\author{
Band 178
}


Jacob Steinwede

\section{Entwicklungschancen sozialdemokratischer Parteien}

Polen, Ungarn, die Tschechische und Slowakische Republik im Vergleich

Westdeutscher Verlag 
Die Deutsche Bibliothek - CIP-Einheitsaufnahme

Steinwede, Jacob:

Entwicklungschancen sozialdemokratischer Parteien:

Polen, Ungarn, die Tschechische und Slowakische Republik

im Vergleich / Jacob Steinwede. - Opladen: Westdt. Verl., 1997

(Studien zur Sozialwissenschaft; Bd. 178)

ISBN-13: 978-3-531-13004-0 e-ISBN-13: 978-3-322-86879-4

DOI: $10.1007 / 978-3-322-86879-4$

NE: GT

Alle Rechte vorbehalten

(C) 1997 Westdeutscher Verlag GmbH, Opladen

Der Westdeutsche Verlag ist ein Unternehmen der Bertelsmann Fachinformation.

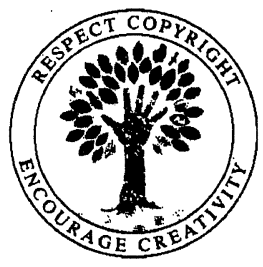

Das Werk einschließlich aller seiner Teile ist urheberrechtlich geschützt. Jede Verwertung außerhalb der engen Grenzen des Urheberrechtsgesetzes ist ohne Zustimmung des Verlags unzulässig und strafbar. Das gilt insbesondere für Vervielfältigungen, Übersetzungen, Mikroverfilmungen und die Einspeicherung und Verarbeitung in elektronischen Systemen.

Umschlaggestaltung: Christine Huth, Wiesbaden

Gedruckt auf säurefreiem Papier 


\section{Vorwort}

Die vorliegende Studie ist die leicht überarbeitete Fassung meiner Dissertation, die im Frühjahr 1995 vom Fachbereich Politische Wissenschaft der Freien Universität Berlin angenommen wurde.

Ohne die wertvolle Hilfe vieler wäre die Untersuchung nicht möglich gewesen. Hier ist an erster Stelle Hans-Dieter Klingemann zu danken. Er hat das Projekt von Anfang an eng begleitet und mit allen Kräften gefördert. Die intensiven Diskussionen am Wissenschaftszentrum Berlin für Sozialforschung - insbesondere in den Colloquien - waren stets eine große Unterstützung. Oskar Niedermayer danke ich, daß er die Arbeit als zweiter Gutachter betreut hat. Für viele Anregungen und kritische Kommentare habe ich Bernhard Weßels sehr zu danken. Verpflichtet bin ich auch Prof. em. Rolf Ulbrich vom Osteuropa-Institut der Freien Universität, der freundlicherweise Übersetzungsarbeiten aus dem Slowakischen übernommen hat. Michael Dauderstädt von der Friedrich-Ebert-Stiftung in Bonn war behilflich bei Materialsuche und bei Kontaktherstellungen nach Polen und in die Slowakei. Heiko Gothe hat bei der Erstellung der Druckvorlage geholfen. Ihnen und anderen sei für ihre Hilfe ausdrücklich gedankt, wobei zu vermerken ist, daß verbleibende Fehler allein zu Lasten des Autors gehen.

Bonn, im März 1996

Jacob Steinwede 


\section{Inhalt}

1. Problemstellung und theoretischer Rahmen 13

1.1. Der Blick auf vier Länder in Ostmitteleuropa: Die Entstehung neuer Parteiensysteme

1.2. Sozialdemokratische Parteien als

Charakteristikum westeuropäischer

Parteiensysteme

1.3. Der entwicklungssoziologische Ausgangspunkt:

Politisierung und Mobilisierung im Postkommunismus

1.4. Spezifische Fragen und Probleme 28

1.5. Die Gliederung der Arbeit

2. Die Vorgeschichte: Traditionen und Diskontinuität

2.1. Entstehung und frühe Entwicklungen der Sozialdemokratien

2.2. Sozialdemokraten und Kommunisten 44

2.3. Liquidation durch Vereinigung

3. Die Vielfalt "linker" Parteien in den postkommunistischen Parteienlandschaften

3.1. Kein sozialdemokratischer Alleinvertretungsanspruch

3.2. Sozialdemokratie im postkommunistischen Polen

3.3. Sozialdemokratie in Ungarn 
3.4. Die "linke" Opposition in der

Tschechischen Republik

3.5. Sozialdemokraten und Postkommunisten in der Slowakischen Republik

3.6. "Sozialdemokratische Spektren", oder: Was heißt sozialdemokratisch?

4. Eine soziale Basis für sozialdemokratische Parteien? Thesen zu Konfliktlinien in den postkommunistischen Gesellschaften

4.1. Eine geringe Bedeutung sozioökonomischer Cleavages

4.2. "Sozialdemokratische Infrastrukturen"

5. Der analytische Rahmen des Ländervergleichs

5.1. Das empirische Konzept und die betrachteten Probleme

5.2. Die Analyse der Parteienebene

5.2.1. Parteiprogramme als Dokumente der Mobilisierungsphase

5.2.2. Der Parteiprogramm-Datensatz

5.2.3. Das Klassifikationsschema

5.2.4. Zur Methode und Interpretation der Inhaltsanalyse

5.3. Die Analyse der Bürgerebene

5.3.2. Die Kombination der Inhaltsanalyse mit Bevölkerungsorientierungen auf einer "Links-Rechts"-Skala 
5.3.3. Zur Analyse der Einstellungsdimensionen und der Zielgruppen

6. Politische Profile auf Parteienebene:

Sozialdemokratische Angebote im Kontext

6.1. Programmatische Profile in den vier Ländern

6.1.1. Ein länderübergreifendes Gesamtbild

6.1.2. Parteiprofile in Polen

6.1.3. Parteiprofile in Ungarn

6.1.4. Parteiprofile in der Tschechischen Republik

6.1.5. Parteiprofile in der Slowakischen Republik

6.2. Polarisierungen in "sozialdemokratischen Spektren" Polens und Ungarns

6.3. Das Ausmaß der Konkurrenz zwischen Sozialdemokraten, Postkommunisten und Kommunisten im Ländervergleich

6.4. Zwischenbilanz

7. Politische Einstellungen auf Bürgerebene

7.1. Dimensionen politischer Einstellungen in Polen, Ungarn, der Tschechischen und Slowakischen Republik

7.2. Sozialistische Wirtschaftsorientierungen bei den Zielgruppen der Parteien

8. Mobilisierungspotentiale für Postkommunisten und Kommunisten

8.1. Politische Konkurrenz und Mobilisierungschancen in der sozialistischen Dimension 
8.2. Vergleich der Mobilisierungskräfte:

Die schwache Sozialdemokratie

9. Zusammenfassende Hypothesen und Ausblick

Tabellenanhang

Tabellenverzeichnis

Verzeichnis der Schaubilder

Verzeichnis der untersuchten Parteiprogramme

Literaturverzeichnis 
"Die Menschen wissen, daß sich die politischen Kräfte in den traditionellen Demokratien zwischen den Polen rechts und links auffächern, deshalb versuchen auch sie, sich so zu definieren und irgendwie in diesem Spektrum zu organisieren."

(Vaclav Havel, Die unvollendete Revolution.

Ein Gespräch mit Adam Michnik, Transit 1992) 